03,08

\title{
Особенности электропереноса в структуре фоторефрактивного легированного кристалла $\mathrm{Bi}_{12} \mathrm{TiO}_{20}: \mathrm{Ru}$
}

\author{
(C) В.Т. Аванесян, К.И. Пайма, В.М. Стожаров \\ Российский государственный педагогический университет им. А.И. Герцена, \\ Санкт-Петербург, Россия \\ E-mail: avanesyan@mail.ru
}

(Поступила в Редакцию 28 сентября 2016 г.)

Изучена проводимость кристаллов $\mathrm{Bi}_{12} \mathrm{TiO}_{20}: \mathrm{Ru}$ на переменном токе в интервале частот $10^{2} \ldots 10^{6} \mathrm{~Hz}$ и температур $293 \ldots 773 \mathrm{~K}$. Анализ экспериментальных данных проводится в рамках модели коррелированных барьерных прыжков. В исследуемом материале потенциальные барьеры обусловлены наличием блочной структуры, дефектов кристаллической решетки, а также присутствием примеси рутения. В легированных монокристаллах титаната висмута определены микропараметры, характеризующие процесс переноса заряда.

Работа выполнена при финансовой поддержке Министерства образования и науки РФ в рамках базовой части государственного задания 24/14-ПГЗ.

DOI: $10.21883 /$ FTT.2017.06.44476.363

\section{1. Введение}

Совершенствование параметров оптических сред на основе кристаллов силленитов связано с необходимостью установления механизмов проводимости и генерации в них носителей заряда. Процессы электротранспорта, в частности, определяют инерционность фотоотклика, одного из критических параметров при формировании объемных голограмм [1].

Известно [2], что фоторефрактивный эффект в кристаллах структуры силленита обусловлен захватом на глубокие центры фотовозбужденных носителей заряда. Для беспримесных кристаллов указанного класса характерно наличие собственных дефектов различного типа, формирующих определенную структуру энергетических уровней в запрещенной зоне [3]. Легирование атомами примеси приводит к образованию дополнительного числа локальных состояний, оказывающих влияние на характер проводимости исходного кристалла [4].

Целью настоящей работы является исследование процесса переноса заряда в переменном электрическом поле в фоторефрактивных кристаллах $\mathrm{Bi}_{12} \mathrm{TiO}_{20}$ (ВТО), легированных рутением.

\section{2. Методика эксперимента}

Изготовление однородных монокристаллов проводилось методом TSSG (top seeded solution growth method) [5] в смешанной атмосфере (85\% воздуха и 15\% аргона) вдоль кристаллографического направления [001]. Легирование синтезированных образцов осуществлялось путем внесения в исходный раствор оксида $\mathrm{RuO}_{2}$ [6]. Для экспериментальных исследований использовались отполированные пластинки размером $7 \times 6 \times 3$, параллельные грани (100). Концентрация примеси в выращенных кристаллах, установленная методом атомно-абсорбционной спектроскопии, составляла величину порядка $n \approx 10^{18} \mathrm{~cm}^{-3}$.

Для определения структуры и особенностей строения легированных кристаллов ВТО был проведен рентгеноструктурный анализ. Измерения осуществлялись на рентгеновском дифрактометре ДРОН-7 с использованием излучения $\mathrm{Cu} K_{\alpha 1}$ при значении энергии рентгеновского кванта, равной $8.047 \mathrm{eV}$. Электрические измерения в интервале частот $f=10^{2} \ldots 10^{6} \mathrm{~Hz}$ выполнялись с применением прецизионного измерителя иммитанса Е7-20. Нагрев образцов осуществлялся в муфельной печи Nabertherm, снабженной контроллером, подъем температуры производился до $773 \mathrm{~K}$ со скоростью $5 \mathrm{~K} / \mathrm{min}$.

\section{3. Экспериментальные результаты и их обсуждение}

На рис. 1 представлена дифрактограмма легированного титаната висмута $\mathrm{Bi}_{12} \mathrm{TiO}_{20}: \mathrm{Ru}$. B процессе ее расшифровки было обнаружено блочное строение и полиморфизм кубической структуры, а именно существование в исследуемом образце двух различных решеток Бравэ. Кристаллический блок, у которого с поверхностью совпадает плоскость (100), следует отнести к простой кубической решетке с постоянной $a=5.078 \AA$, а блоки (422) и (600) - к гранецентрированной кубической структуре кристалла с постоянной $a=5.502 \AA$, причем количество последних значительно превышает число простых кубических решеток. Размеры кристаллитов $D$ вычислялись по формуле Селякова-Шерерра [7]

$$
D=K \lambda / w \cos \theta,
$$

где $K$ - безразмерный коэффициент формы частиц (постоянная Шеррера), $\lambda$ - длина волны рентгеновских лучей, $w$ - ширина рефлекса на полувысоте в радианах, $\theta-$ угол дифракции рентгеновских лучей. 


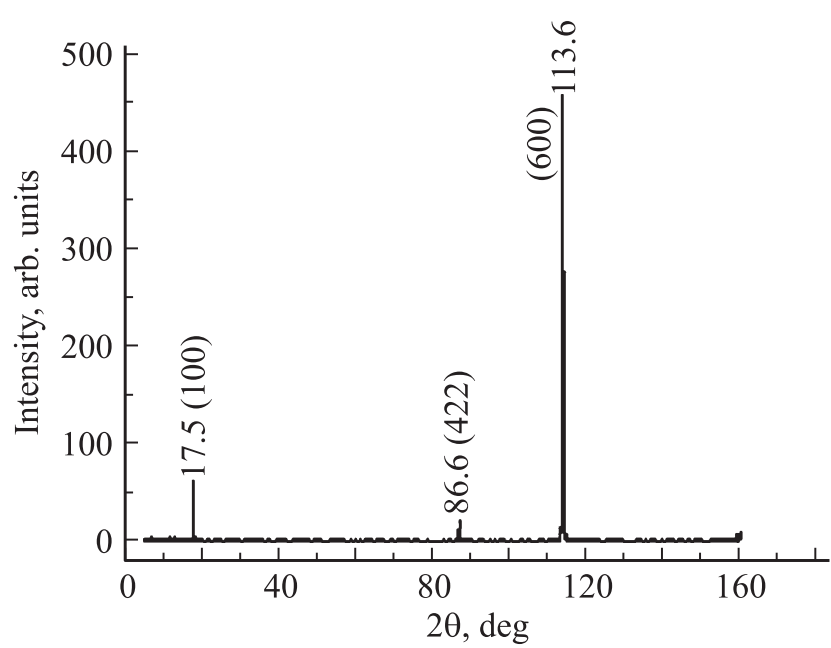

Рис. 1. Дифрактограмма легированного кристалла титаната висмута $\mathrm{Bi}_{12} \mathrm{TiO}_{20}: \mathrm{Ru}$.

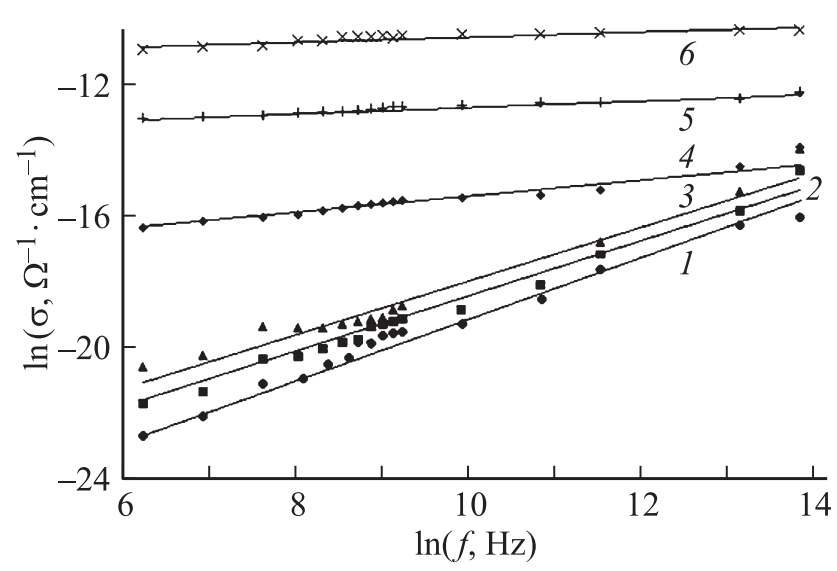

Рис. 2. Частотная зависимость удельной электропроводности кристалла $\mathrm{Bi}_{12} \mathrm{TiO}_{20}: \mathrm{Ru}$ при температурах: $1-293,2-373$, $3-473,4-573,5-673,6-773 \mathrm{~K}$.

Расчетное значение параметра $D$ оказалось равным порядка $100 \mathrm{~nm}$, что подтверждает наличие в исследуемом кристалле структурных элементов - блоков и, таким образом, возможность присутствия в образце границ разделов дислокаций различного типа [8].

Для разных температур нагрева образцов были получены частотные зависимости удельной электропроводности $\sigma(f)$ (рис. 2), значения которой рассчитывались по данным измерений методом импедансной спектроскопии. Как показывает анализ экспериментальных результатов, во всей частотной области приведенные зависимости удовлетворяют соотношению

$$
\sigma=A f^{s}
$$

где $A-$ постоянный коэффициент, определяемый геометрией кристалла, $s$ - показатель степени, соответствующий значению порядка 0.8 для интервала температур $T=293 \ldots 473 \mathrm{~K}$.
Приведенная величина параметра $s$ является одним из признаков существования механизма переноса носителей зарядов прыжкового типа [9]. Известно [10], что перенос заряда в кристаллах силленита осуществляется в основном электронами и дырками, кроме того, результаты последних исследований [11] позволяют говорить о дополнительном вкладе в процесс электропереноса ионной проводимости. Движение носителей в переменном поле ограничено как потенциальными барьерами на границах разделов, так и наличием собственных дефектов кристаллической решетки.

В приближении модели Пайка [12], учитывающей прыжки с распределением высоты потенциальных барьеров, присутствующих в структуре кристалла, перемещение носителей заряда характеризуется выражением

$$
1-s=6 k T / W_{m},
$$

где $W_{m}$ - максимальная высота потенциального барьера, $k$ - постоянная Больцмана. С учетом величины параметра $s$ расчетное значение $W_{m}$ при $T=293 \mathrm{~K}$ оказалось равным $0.9 \mathrm{eV}$.

На рис. 3 представлена температурная зависимость показателя степени частотной характеристики удельной электропроводности $s(T)$. Уменьшение значения параметра $s$ при повышении температуры удовлетворяет положениям модели коррелированных прыжков через барьер (correlated barrier hopping), высота которого зависит от внутреннего положения дефектных центров, определяемого кулоновским взаимодействием [13].

На рис. 4 приведена температурная зависимость электропроводности в координатах Мотта $\ln \sigma\left(T^{1 / 4}\right)$ [14]. Полученная кривая отвечает линейной зависимости, что может свидетельствовать о переносе заряда за счет прыжков электронов и дырок по локализованным состояниям, лежащим в узкой полосе энергий вблизи уровня Ферми. В этом случае значение боровского радиуса локализации носителей заряда можно вычислить по

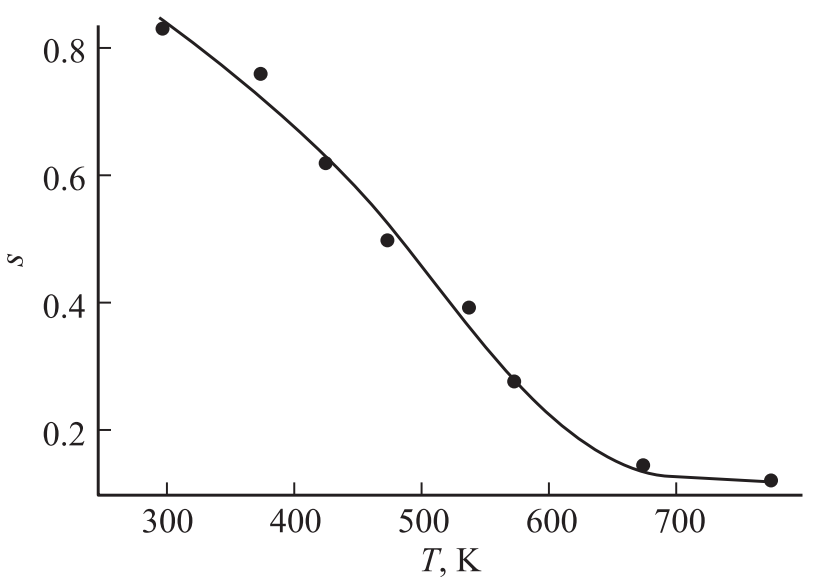

Рис. 3. Температурная зависимость показателя степени $s$ в зависимости $\sigma(f)$ для кристалла $\mathrm{Bi}_{12} \mathrm{TiO}_{20}: \mathrm{Ru}$. 


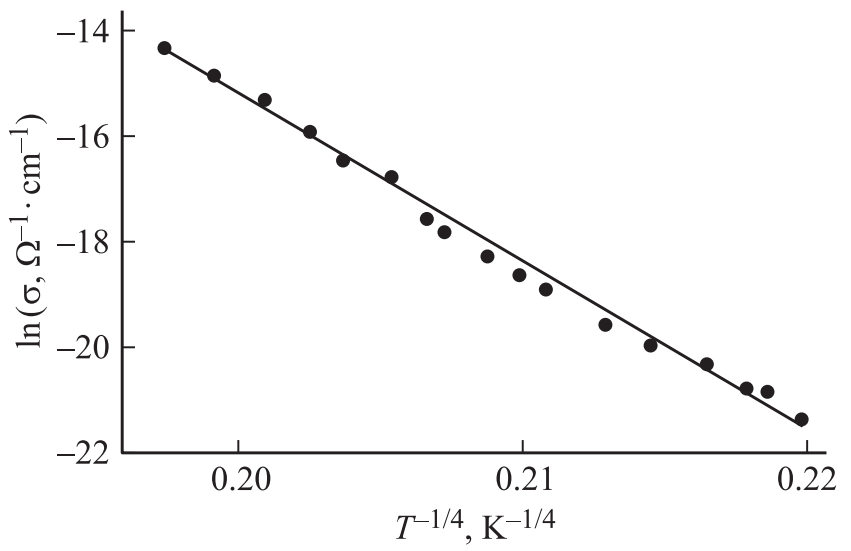

Рис. 4. Температурная зависимость удельной электропроводности кристалла $\mathrm{Bi}_{12} \mathrm{TiO}_{20}: \mathrm{Ru}$ в координатах Мотта.

формуле [15]

$$
r=e^{2} / 2 \varepsilon_{0} \varepsilon W_{m},
$$

где $e-$ заряд электрона, $\varepsilon_{0}-$ электрическая постоянная и $\varepsilon$ - диэлектрическая проницаемость, величина которой рассчитывалась с применением стандартного выражения [16]. Расчетное значение параметра $r$ оказалось равным $8 \AA$. Средняя длина прыжка носителей заряда по локализованным состояниям для заданной температуры и частоты измерения определяется выражением [17]

$$
R=\frac{1}{2} r \ln \left(v_{\mathrm{ph}} / f\right),
$$

где $v_{\mathrm{ph}}-$ фононная частота, значение которой, аналогично данным [18], взято равным $10^{12} \mathrm{~Hz}$. При $T=293 \mathrm{~K}$ и $f=10^{3} \mathrm{~Hz}$ значение $R$ для исследуемых образцов составило величину порядка $82.8 \AA$, что значительно превышает радиус локализации носителя заряда.

В случае коррелированных барьерных прыжков величина плотности локальных состояний вблизи уровня Ферми описывается соотношением [19]

$$
N=\frac{16}{T_{0} k r^{3}},
$$

где значение параметра $T_{0}$ определяется наклоном прямой $\ln \sigma\left(T^{1 / 4}\right)$ и для рассматриваемого случая составляет $2.84 \cdot 10^{2} \mathrm{~K}$. Оценка плотности локализованных состояний приводит к величине $N=4.8 \cdot 10^{23} \mathrm{eV}^{-1} \cdot \mathrm{cm}^{-3}$.

Причиной формирования большинства локальных состояний в кристаллической решетке ВТО является изоморфизм ионов $\mathrm{Bi}^{3+}$ и $\mathrm{Ti}^{4+}$ в тетраэдрах $\mathrm{MO}_{4}$ (дефект $\mathrm{BiMO}_{4}$ ) [20]. Вместе с тем отмечается [21] возможность образования дефекта $\mathrm{BiMO}_{3}$ при замещении титана ионами $\mathrm{Bi}^{3+}$, координируемыми тремя атомами $\mathrm{O}$ и обладающими стерически активной неподеленной парой электронов в направлении четвертого отсутствующего атома кислорода. Указанные группы $\mathrm{BiMO}_{3}$ и $\mathrm{BiMO}_{4}$, известные как антиструктурные дефекты [22], обусловливают наличие в кристаллах силленитов спектра локальных состояний вблизи уровня Ферми, по которым осуществляется перенос носителей заряда. В процессе роста кристаллов позиция катиона Ті может оставаться и вакантной, формируя дефект $\mathrm{VO}_{4}$.

Атом рутения может существовать в трех валентных состояниях $\mathrm{Ru}^{3+}, \mathrm{Ru}^{4+}$ и $\mathrm{Ru}^{5+}$ [23]. Таким образом, в процессе легирования исследуемых кристаллов вероятным является искажение кислородных тетраэдров структуры ВТО с образованием кислородных вакансий, способных захватить электрон в соответствии с условием компенсации. Атомы примеси могут замещать как ионы $\mathrm{Bi}^{3+}$ в искаженных октаэдрах, так и ионы $\mathrm{Ti}^{4+}$ в центрах кислородных тетраэдров, формируя при этом глубокие и мелкие локальные состояния. Дополнительным источником дефектообразования является наличие установленной в результате рентгеноструктурного анализа блочной структуры образца $\mathrm{Bi}_{12} \mathrm{TiO}_{20}: \mathrm{Ru}$, что в свою очередь может обусловливать наблюдаемое резонансное поведение диэлектрической проницаемости на высоких частотах измерения [16].

\section{4. Заключение}

Анализ результатов исследования проводимости легированных кристалла титаната висмута свидетельствует о характере переноса носителей заряда, связанного с коррелированными прыжками через барьер, высота которого определяется положением центров, формируемых за счет наличия собственных и примесных дефектов. Установленное методом рентгеноструктурного анализа присутствие кристаллических блоков представляет собой дополнительный источник дефектообразования в кристалле $\mathrm{Bi}_{12} \mathrm{TiO}_{20}$, легированном рутением.

Авторы выражают признательность профессору M.М. Господинову (Институт физики твердого тела Болгарской академии наук) за предоставленные образцы.

\section{Список литературы}

[1] М.Г. Кистенева, Е.С. Худякова, С.М. Шандаров, А.С. Акрестина, В.Г. Дю, Ю.Ф. Каргин. Квантовая электрон. 45, 685 (2015).

[2] В.К. Малиновский, О.А. Гудаев, В.А. Гусев, С.И. Деменко. Фотоиндуцированные явления в силленитах. Наука, Новосибирск. 1990. 160 с.

[3] Ю.Ф. Каргин, В.И. Бурков, А.А. Марьин, А.В. Егорышева. Кристаллы $\mathrm{Bi}_{12} M_{x} \mathrm{O}_{20}$ со структурой силленита. Синтез, строение, свойства. Буква, М. (2004). 312 с.

[4] Т.В. Панченко, К.Ю. Стрелец. ФТТ 51, 277 (2009).

[5] V. Belruss, J. Kalnajs, A. Linz. Mater. Res. Bull. 6, 899 (1971).

[6] V. Marinova, S.H. Lin, V. Sainov, M. Gospodinov, K.Y. Hsu. J. Opt. A 5, S500 (2003).

[7] В.Б. Вайнштейн, Л.М. Инденбом, В.М. Фридкин. Современная кристаллография. Наука, М. (1979). Т. 2. 367 с.

[8] Р.Н. Бекимбетов. Неорган. материалы 38, 953 (2002).

[9] В.В. Пасынков, В.С. Сорокин. Материалы электронной техники. Высш. шк., М. (1986). 363 с. 
[10] А.Ю. Кудзин, С.Н. Пляка, Г.Х. Соколянский. ФТТ 42, 839 (2000).

[11] V. Marinova, E. Goovaerts. Bulg. Chem. Commun. 45, 218 (2013).

[12] G.E. Pike. Phys. Rev. 6, 1572 (1972).

[13] S.R. Elliott. Phil. Mag. 36, 1291 (1977).

[14] Б.И. Шкловский, А.Л. Эфрос. Электронные свойства легированных полупроводников. Наука, М. (1979). 4176 с.

[15] Pollak. Phil. Mag., 23, 519 (1971).

[16] В.Т. Аванесян, К.И. Пайма. ФТТ 58, 1510 (2016).

[17] Н. Мотт, Э. Дэвис. Электронные процессы в некристаллических веществах. Мир, М. (1982). 368 с.

[18] В.Т. Аванесян, М.П. Севрюгина. Материалы Междунар. науч.-техн. конф. Intermatic-2012. М. (2012). Ч. 2. С. 124.

[19] M. Pollak. Phys. Rev., 122, 1742 (1961).

[20] A. Lima, M. Lalic. J. Phys. Condens. Matter. 25, 495505 (2013).

[21] В.Т. Аванесян, Н.М. Абрамова. ФТТ 57, 2112 (2015).

[22] В.Т. Аванесян, Н.М. Абрамова. ФТТ 57, 1084 (2015).

[23] V. Marinova, Mei-Li Hsieha, Shiuan Huei Linb, Ken Yuh Hsu. Opt. Commun. 203, 377 (2002). 